\title{
LAS EXIGENCIAS DE UNA ÉTICA DEL CONOCER
}

\author{
María Lucrecia Rovaletti*
}

Resumen: El «deseo de conocer», una de las aspiraciones fundamentales del hombre, se conjuga con la ambición o la competitividad, fenómenos que pueden desviarlo de sus objetivos desinteresados. Actualmente se arroja una sospecha sobre esta libido sciendi, que ha devenido una libido dominandi, donde se combinan la valorización legítima del poder y la idolatría del progreso.

Sin embargo, las posibles desviaciones no deben ser imputadas solamente al deseo de conocer mismo, sino también al sistema social que, por medio de las instituciones, obliga a los investigadores a librar entre ellos una competencia permanente a través de proyectos y publicaciones, conminándolos a plegarse a las leyes de la concurrencia económica o entrar en el juego de la competición internacional por el prestigio.

Como miembros de una comunidad científica con intereses propios, es preciso que defendamos la autonomía de esta libido cognoscendi frente a los decisores sociales en la medida que de ellos dependen los recursos económicos para la investigación. La investigación aún desinteresada constituye un capital importante para el enriquecimiento cultural de la sociedad, pero es importante permanecer vigilante pues el hombre está en el centro de las investigaciones como también de sus aplicaciones.

Palabras clave: Libido, competitividad, progreso, prestigio, investigación desinteresada

\section{DEMANDS OF AN ETHICS OF KNOWLEDGE}

Abstract: The desire of knowledge, one of man's most important goals, there are also mixed wishes of other type, like ambition or competition, which can deviate him from his uninterested objectives. That is why there are many people who throw a suspect on this libido sciendi that has become a libido dominandi where the legal valorization of power and the idolatry of progress are combined. It will be the ethic comisions or comites to play a calming function that can work as a boundary to this cultural anguish.

However, these possible deviations must not only be atributed to the desire of knowing in itself, but to the social system, which, troughout the institutions, compels investigators to compete among themselves with projects and publications, and obliges them to enter either into an economic competition or into an international confrontation in order to obtain recognition.

As members of a scientific comunity, with its own interests, it is necessary for us to defend the autonomy of this libido cognoscendi in front of those who take social decisions, in the measure that economical resources for investigation depend on them. Uninterested investigation is still very important for the cultural wellfare of society, but it is important to be on guard, as man is not only in the centre of investigations, but also of its applications.

Keywords: Libido, competitivity, progress, prestige, uninterested investigation

\section{AS EXIGÊNCIAS DE UMA ÉTICA DO SABER}

Resumo: O "desejo de conhecer" uma das aspirações fundamentais do homem, conjuga-se com a ambição ou a competitividade, fenômenos que podem promover desvio de seus objetivos desinteressados. Atualmente lança-se suspeita sobre a "libido sciendi" que vem se transformando em "libido dominandi", situação que combina valorização legítima do poder e a idolatria do progresso.

Entretanto, os possíveis desvios não devem ser imputados somente ao desejo de conhecer, mas, também, ao sistema social que, por meio das instituições, obriga os investigadores a demonstrarem competência permanente através de projetos e publicações compelindo-os a submeterem-se às leis da concorrência econômica ou adaptarem-se ao jogo da competição internacional pelo prestígio.

Como membros de uma comunidade científica com interesses próprios, é preciso que defendamos a autonomia da "libido cognoscendi" frente aos determinantes sociais na medida em que deles dependem os recursos econômicos para investigação. A investigação ainda que desinteressada constitui valor importante para o enriquecimento cultural da sociedade, mas é necessário permanecer vigilante pois o homem encontra-se no centro das investigações, assim como as aplicações advindas das mesmas.

Palavras chave: Libido, competitividade, progresso, prestígio, investigação desinteressada

* Doctora en Medicina. Profesora Investigadora del Consejo Nacional de Investigaciones Científicas y Técnicas (CONICET), Universidad de Buenos Aires, Argentina.

Correspondencia: mIrova@psi.uba.ar 
"Creéis que las ciencias hubieran podido nacer y hacerse grandes si antes no hubieran existido magos, alquimistas, astrólogos y hechiceros, con hambre y sed de poderes ocultos y prohibidos?" (F. Nietzsche, La voluntad de poder.)

Si hay características que pueden ser resaltadas como propias del espíritu humano son, por un lado, el impulso a trascender e ir más allá de los límites transformando la realidad objetiva y, por otro, el empeño constante en perfeccionar la capacidad de acción y en modificar las situaciones. La ciencia deja ahora de ser un mero conocer para convertirse en un operar. Y ese hábito así adquirido bien pronto se convierte en una exigencia que legitima que las fronteras pueden y tienen que ser violadas. El confín neto que separa lo deseable de lo imposible está delineado por los recursos disponibles y la habilidad tecno-científica a disposición.

Esta actitud de la racionalidad técnica en tanto expresión acentuada de la voluntad de poder constituye la consecuencia por excelencia del programa de la Modernidad que culmina con el dominio del mundo y la realidad, incluyendo al hombre. Esto conlleva una inversión de los intereses epistemológicos del sujeto cognoscente y un paso a un segundo plano de la verdad teórica. La tecnociencia ya no pregunta por la naturaleza o la estructura interna del objeto, sino que busca una verdad operativa dirigida primordialmente a su manipulación.

Ahora bien, la instauración de este paradigma de la racionalidad tecnológica no se produce al margen de la realidad cultural, social, política y económica sino que, como toda racionalidad, responde a un conjunto de exigencias históricas determinadas por las circunstancias de la época. En efecto, si en otros tiempos el científico se mantenía, "encerrado en su laboratorio como un alquimista, sólo, pobre, sospechado y mal conocido, no teniendo otros medios más que el que el sostén nacional que se le prodigaba, hoy en día está integrado a equipos, fortificado por las finanzas públicas, respaldado por los favores del mundo, en intercambio incesante con sus pares, fustigado por el éxito. Las universidades se pelean por ellos, los jurados los cubren de flores... La brusca complicidad de la sociedad le permitió a la ciencia lanzarse hacia todos los horizontes a la vez" $(1)^{1}$.

A pesar de ello, la ciencia actualmente ignora con precisión hacia dónde se dirige. De esa especie de drama que opera en los laboratorios no se sabe cuál será su final, cuáles sus consecuencias. Se habla de una moratoria. "Je m'arrete", insiste Jean Testart, mientras se anudan por otras partes complicidades de todo tipo, como el afán de novedades, el lucro de las industrias, la mera lógica de la eficiencia.

"El progreso de la civilización, entendida ésta como desarrollo científico tecnológico, alcanza así su estadio crítico y es puesto en tela de juicio ante la latencia paradójica de peligros extremos para el conjunto de la humanidad misma" (2).

La nueva biomedicina: conocimiento e instrumentalización.

Una de las principales beneficiarias de esta convicción y este compromiso del iluminismo con el progreso científico, ha sido y es la medicina contemporánea. Comprometida con el progreso sin límites, ella se ha mostrado enormemente ambiciosa y expansiva, como si

\footnotetext{
1 En general, se puede afirmar esto en los países donde el porcentaje del presupuesto nacional destinado a la investigación científica y tecnológica es significativo.
} 
estuviera imbuida de la creencia de que con rigor científico, energía y apoyo económico suficientes no habría enfermedades que no pudieran ser curadas o remediadas. ¿No habrá en esta voluntad de conocer ilimitada un rechazo a la finitud humana y una confrontación con la muerte para negarla?

A pesar de las profundas transformaciones que las ciencias biomédicas y sus prácticas han acarreado a la vida humana, sin embargo no todas traducen optimismo sino más bien ponen al descubierto profundos enigmas y dilemas.

La protección o el restablecimiento de la salud han sido relegados por el deseo de conocer; mas aun esta motivación ha cedido actualmente a un proceso de cosificación e instrumentalización, precisamente en un terreno que se caracteriza por la noble causa de la "protección" de la salud. Esta problemática nos lleva a interrogarnos sobre los procesos de la investigación, sobre la validez de sus fines y la aceptabilidad o rechazo de sus medios. En última instancia se trata de saber cuáles son las fuentes de legitimidad y de autoridad de quienes deciden estas prácticas.

Indudablemente que existe para la profesión médica una "obligación de investigar" que, aunque pareciera en primera instancia ser independiente del deber de curar y soslayar el sufrimiento, sin embargo tarde o temprano puede ser legitimada por los resultados útiles que pueda en un futuro ofrecer a la salud de la humanidad. Mas allá que se pueda o no alcanzar un beneficio directo para la salud, la investigación biomédica queda definida como un estudio, ensayo, o experimentación practicada sobre la persona humana, dirigida al conocimiento biológico-médico del hombre enfermo y del hombre sano en el ambiente ordinario, artificial o extremo.
Es preciso ahora dilucidar dos interrogantes. Por un lado, las implicancias éticas de los nuevos tratamientos de dirección diagnóstica, terapéutica, y aun preventiva; y por otro cuáles son las consecuencias de los ensayos experimentales cuando la finalidad no es la protección ni el restablecimiento de la salud. Una motivación altruista busca responder y justificar los estudios en los sujetos considerados sanos estimando los beneficios que puedan ofrecer a futuro: la argumentación permite el paso de la ética centrada en el bien del individuo -propia de la relación médico-enfermoa una ética de la solidaridad centrada en el bien colectivo.

¿Pero esta justificación a través de una ética comunitaria no pone al descubierto una cierta culpabilidad por explorar el ser humano simplemente para conocerlo, como ocurriera con las primeras disecciones de cadáveres? ¿No contribuye con ello a crear el mito del sabio benefactor de la humanidad, cuando las motivaciones humanitarias de la investigación son muy a menudo discutibles, puesto que aumentan nuestra esperanza de vida pero pueden derivar en la instrumentalización y cosificación del ser humano? ¿Hasta cuándo podrá uno congratularse por la aceleración de estos avances, fruto de un esfuerzo interdisciplinario puesto al servicio de los enfermos? ¿No habrá que pensar además quién controla las posibles aplicaciones de la investigación?

Por ello, la mayoría de los países han adoptado legislaciones relativas a la protección de personas que se prestan a las investigaciones biomédicas, es decir a "ensayos, estudios y experimentaciones practicadas sobre el ser humano en vista del desarrollo de los conocimientos biológicos y médicos" (Ley de Diciembre 1998, en Francia Art. L 209 -1). Se habla de un conocimiento biomédico, cuya licitud depende de la colaboración estrecha entre la 
biología que atiende esencialmente el acrecentamiento del saber y la medicina que busca prevenir, curar, y cuidar o paliar(3). De este modo, los actos con una dirección puramente cognitiva de algún modo tienen que referirse a la salud humana.

Esto anuda dos perspectivas en torno a la investigación. Desde el punto de vista jurídico, el sujeto enfermo está ligado al médico por una convención que lo obliga a éste a dispensarle sus cuidados conforme a los datos obtenidos por la ciencia y reconocidos por la sociedad. Desde el punto de vista ético, el médico en su tarea se dirige primariamente al individuo al que deberá informar adecuadamente de las acciones a recibir y, en este sentido, el sujeto como objeto de tratamiento deja de ser un ser pasivo asociado a ese desolador status de "cobayo" librado a misteriosas prácticas, y se constituye ahora en un colaborador de la investigación.

\section{Unas motivaciones equívocas}

Las motivaciones humanas de investigación a menudo resultan cuestionables y llevan a desconfiar de las eventuales aplicaciones. La persona acepta riesgos para el bien de la colectividad, pues el altruismo está valorizado socialmente, sin embargo no siempre la búsqueda cognitiva puede justificar moralmente la aplicación de procedimientos de investigación o experimentación que puedan ser agresivos, arriesgados o indiscretos para el ser humano.

Suele ocurrir a menudo que el anhelo de poder personal cambie insidiosamente el amor al prójimo en amor propio y arroje sus tentáculos a las naturalezas predispuestas: del altruismo a la vanidad. ¿Cómo no sufrir la fascinación del poder en una época donde la medicina es, entre todas las ciencias, la más presti- giosa en razón de los grandes cambios que produce, de las expectativas que logra cumplir y de los caminos que puede abrir constantemente? La ciencia reemplazó a la ignorancia, y también la modestia. Todo un espectáculo comienza cuando los camarógrafos y reporteros se precipitan en busca de una entrevista y una fotografía a los investigadores renombrados, cuando los editores tratan de arrancarles sus manuscritos mientras las empresas promotoras sueñan con sus éxitos.

A su vez los intereses financieros suelen teñir a las investigaciones de algunas desviaciones ajenas al interés cognoscitivo. Por ejemplo, los proyectos sobre biotecnología que representan ya cuantiosas inversiones y que se irán multiplicando cada vez más, han hecho retroceder principios jurídicos respecto de las patentes de organismos vivientes. Los argumentos invocados son evidentemente generosos: es necesario aumentar los rendimientos de la naturaleza para satisfacer las necesidades de una demografía en crecimiento veloz, se precisan vegetales transgénicos, capaces de matar sus propios parásitos, de gran resistencia y de gran potencialidad proteica. Sin embargo, a pesar de tanta ciencia, se ignoran las consecuencias de esta revolución prodigiosa. ¿Cómo se comportarán las especies vecinas en contacto con organismos modificados? ¿Cómo reaccionarán los suelos? Las opiniones son divergentes. Algunos dicen que las bacterias, los vegetales, los insectos producidos en los laboratorios y luego dejados en la naturaleza, se eliminarán por el juego de la selección natural. Otros, más alarmados, consideran que invadirán todos los medios sin discernimiento y conducirán a una debacle ecológica. Frente a estas dudas, la codicia del interés financiero seguro de sí mismo permanece en posición fuerte.

Por su parte la praxis médica ofrece tal complejidad en sus procedimientos que sus consecuencias llevan a preocupar a la socie- 
dad y a cuestionar la legitimidad de estos avances. A pesar de su altruismo, la medicina no puede garantizar que no dañará, que defenderá el "primun non nocere". Los efectos contradictorios acentúan gravemente la conflictividad de las decisiones, arrojando una sombra sobre la imagen neutral y objetiva que la misma ciencia se otorga.

Como bien afirma France Queré, “es un hecho que la medicina no ha podido lavarse de toda sospecha: el gran debate sobre la moralidad que se abrió en los países industrializados saca a la luz, tardíamente, una culpabilidad que ha flotado siempre sobre una disciplina sin embargo dotada de un rostro de buen samaritano"(1). No vamos a recordar las duchas heladas para los alienados, ni las purgas para los cancerosos, ni las ventosas para los cardíacos, ni las sangrías para los tuberculosos; ni cuando la medicina desesperaba y cambiaba los guantes para asumir un control policíaco: los coléricos eran sofocados entre colchones, los apestados eran encerrados en sus casas, los leprosos eran provistos de campanillas para dispersar al vecindario o los alienados eran maniatados o enjaulados como bestias. La burla de Molière era certera cuando decía que los hombres mueren por sus remedios más que por sus enfermedades.

\section{Aquel antiguo deseo de conocer}

Indudablemente que la ciencia para avanzar necesita experimentar también sobre el hombre, y para convertirlo metodológicamente en objeto de conocimiento debe hacer abstracción de su singularidad. Para lograr sus objetivos buscará por un lado obtener resultados prácticos inmediatos o al menos visibles y, por otro, hacer progresar el conocimiento del hombre mismo. Habrá que determinar entonces si los resultados obtenidos contribuyen al progreso de la ciencia pero también al mejoramiento de la calidad de vida.

Ahora bien, esta curiosidad hoy es vivida de modo ambivalente, con excitación y culpabilidad, es como si un daîmon nos inspirara y nos llevara más allá de nosotros mismos, haciéndonos transgredir barreras invisibles y violar la intimidad del objeto: curiosidad agresiva, a veces letal. El deseo de saber se conjuga ahora con deseos de otra naturaleza, la ambición o la competitividad que pueden reforzar la investigación, pero también desviarla.

Ahora, la frase "todos los hombres desean saber" del comienzo de la Metafisica de Aristóteles no lleva al cumplimiento de la "eudaimonía" propia de la vida ética. En efecto, Aristóteles reservaba la vida del estudio para ciertos hombres que tienen a la vez el gusto por la ciencia y el placer de consagrarse a ella, mientras que la mayoría encuentra su felicidad en otros modos de vida.

En Tres ensayos de una teoría sexual, Freud hace referencia a una "pulsión de dominio", sin carácter sexual, pulsión de apropiación de lo otro como objeto. Suele considerársela a veces de "instinto" y se la compara con la necesidad de comer o de reproducirse (perpetuarse). Esta tendencia, acompañada por la indiferencia al dolor del otro, se sublima voluntariamente en una pulsión de ver y saber, "es una pulsión no sexual que no se une sino secundariamente a la sexualidad y cuyo fin es dominar al objeto por la fuerza", señala Laplanche. Este concepto,

"evoca la idea de presa, captura, incluso de apoderamiento.... A nivel interpersonal se trata de una acción de apropiación por desposesión del otro: es un embargo, una confiscación que representa una violencia infligida y sufrida que perjudica al otro por una usurpación sobre su dominio privado, es decir a 
través de la...siendo la intención reducir al otro a la función y al estatus de objeto enteramente asimilable"(4).

Por su parte, Pascal colocaba la libido sciendi como una de las manifestaciones de la concupiscencia humana fruto del pecado, que nos pone a espaldas de Dios. Sin embargo, no se vislumbra aquí un posible enjuiciamiento a la ciencia en términos de beneficencia o maleficencia, ni por los riesgos potencialmente peligrosos, ni tampoco por la utilización de la actividad científica al servicio del poder. Tanto para Pascal como para Aristóteles, esta curiosidad natural del hombre no se limita al solo deseo del conocimiento científico, sino que engloba ciertas actividades diversas del espíritu.

Tampoco se trata de una crítica asociada al juicio revolucionario como ocurrió con aquellos que habían declarado que "la república no tiene necesidad de sabios" en el momento de condenación de Lavoisier. Más que una apreciación moral definitiva sobre el valor del conocimiento o sobre el instinto que nos empuja a conocer, se translucían allí ciertas conjeturas políticas, pero también opiniones sociales que consideraban al saber desinteresado en la más baja escala de los valores socialmente reconocidos: se cuestionaba el status social de la ciencia, más que interrogarse sobre la curiosidad natural del hombre.

Para Monod la investigación científica constituye un imperativo moral, tesis que hoy no podría suscribirse totalmente, por lo menos no para todo el mundo. Si se compara el pensamiento de Pascal con los escritos de Monod se nota que los dos colocan al hombre individual delante de una elección ética de valores en éste, o una jerarquía de "órdenes" en aquél. Ambos proponen "un ideal que trasciende al individuo al punto de justificar que éste se sacrifique por necesidad"(5).
El Comité Consultivo de Etica(6) en Francia opina mayoritariamente que el deseo de conocer es una tarea natural del hombre, $\mathrm{y}$ todo lo que es natural es bueno. En este sentido, la investigación debe ser estimulada más que frenada, y las posibles desviaciones no deben ser imputadas al deseo de conocer mismo, sino al sistema social que, a través de las instituciones, obliga a los investigadores a librar entre ellos una competición permanente a través de proyectos y publicaciones, que los conmina a plegarse a las leyes de la competencia económica o entrar en el juego de la disputa internacional por el prestigio.

Es verdad que el "derecho de conocer" implica la libertad humana y el "deber" de conocer justifica los esfuerzos humanos para ello: cada uno, a nivel individual se configura acorde a sus elecciones personales de vida, pero no puede olvidar que también pertenece a una comunidad científica y moral. No basta con considerar la elección de cada investigador como un acto individual, ya que la ciencia se ha convertido en un problema que atañe a toda la sociedad. Las grandes orientaciones de la investigación son ahora objeto de votos parlamentarios, de financiamiento a través de fondos públicos, hasta existen comisiones nacionales nombradas para estudiar los límites de aceptabilidad de los estudios.

Se puede afirmar a grandes rasgos que en nuestras sociedades desarrolladas se reconoce a la investigación como un bien en sí, con implicancias directas en la comunidad. Sin embargo, la tensión surge entre la dirección humanitaria y la dirección cognitiva de la ciencia. La cuestión reside en compatibilizar el conocimiento tomado como valor y los otros valores a los cuales relacionamos nuestras elecciones éticas, como el bienestar, la libertad y la justicia. 


\section{Libido cognoscendi o libido dominandi}

A pesar de la tan repetida objetividad, la investigación aún no ha podido ser expurgada de los elementos irracionales inherentes al sujeto investigador. Este encubrimiento por parte del científico que investiga, requiere ahora ser también objeto de crítica epistemológica para poner así fin a los mitos cientificistas de estos hombres sabios benefactores(7).

Son muchos los que arrojan actualmente una sospecha sobre esta libido cognoscendi que ha devenido una libido dominandi, donde se combinan la valorización legítima del poder y la idolatría del progreso. El avance acelerado y constante de la ciencia inquieta y engendra una necesidad de seguridad ante la proliferación de nuevos saberes y poderes. Serán las comisiones de ética, las que ejerzan un rol tranquilizador que funcione como barrera de contención ante esta "angustia cultural"(3). Mientras la comunidad científica se defina por criterios de "excelencia", no podrá lograse una comunidad moral, y los científicos a falta de competencia ética siempre estarán expuestos a ser recusados a título diverso. Como bien muestra Anne Rice: "El futuro es el tejido de posibilidades entrelazadas, algunas de las cuales se convertirán en probabilidades, y unas pocas en inevitabilidades, pero hay sorpresas entretejidas en la trama y la urdimbre que pueden desgarrarlas"(8).

En este sentido, Memmi considera que el discurso ético constituye el producto de una posición inconfortable de estos sabios moralizadores -de los Comité Clínicos, Comité de Investigación, Comisiones nacionales...que se hallan tironeados entre dos fuegos. Por un lado, tienen que tener confianza en el progreso y exaltar a la ciencia por su capacidad de resolver ella misma todas las cuestiones que sostiene. Por otra parte, están obligados a condenar el abuso de ciertas prácticas y ciertas aspectos de la postura científica (9).

Ahora bien, a pesar de todos estos cuestionamientos a la investigación, sus aplicaciones se difunden ampliamente. La "tecnociencia", como expresión acentuada de la voluntad de dominio del hombre moderno, exige la disponibilidad y la utilidad pragmática de los conocimientos; más aún, ella ya no puede ser comprendida sólo en términos de una "lógica de los conocimientos" ya que está invadida por la competencia desenfrenada, la rentabilidad industrial y la especulación bursátil. El mundo de los descubrimientos biológicos y de la innovación biomédica se ha convertido en un campo donde se habla cada vez más en términos de mercado, de portafolios de patentes, estrategias de grupos y alianzas a escala transnacional; hasta los eventos científicos parecieran constituir una buena ocasión para orientar y hasta reorientar el tema de investigación de los científicos.

"Investigación científica y desarrollo tecnológico sin trabas, por una parte, y supervivencia humana del hombre por la otra, parecen constituir los polos de un conflicto social y plantean el problema de las relaciones entre ética y ciencia, hoy formulado en los términos de neutralidad o compromiso axiológico de la ciencia. Todo parecería indicar que las situaciones-límite a las que la humanidad ha llegado introducen de manera dramática y compulsiva en la ciencia los valores que ella, en nombre de su propia pureza, había expulsado de su seno"(2).

Como miembros de una comunidad científica con intereses propios, se torna urgente defender la autonomía de esta libido cognoscendi frente a los decisores sociales en la medida que de ellos dependen los recursos 
económicos para la investigación. La investigación científica constituye un capital importante para el enriquecimiento cultural de la sociedad, pero es importante permanecer vigilante porque es el hombre el que está en el centro de las investigaciones como también de sus aplicaciones. "Buscar en la dignidad humana una ética para la ciencia, impone también que la ética intelectual de la ciencia sea respetada"(6).

El respeto a la "dignidad de la ciencia" es sin duda parte del respeto a la dignidad humana, pero la coherencia de estos dos aspec- tos no siempre se presenta como evidente. Será el deber de preservar a las personas humanas el que fije los límites de la empresa del conocer.

Ante esta modernidad tardía que se caracteriza por la expansión temporal de las opciones que lleva por ello mismo a la extensión de los riesgos (Berian), no puedo yo evadirme. Porque, “...viviendo mi tiempo puedo comprender los demás tiempos, ahincándome en el presente y en el mundo... puedo ir más allá. No tenemos por qué temer que nuestras opciones y nuestras acciones restrinjan nuestra libertad"(10).

\section{Referencias}

1. Queré F. L'éthique et la vie. París: Odile Jacob; 1991

2. Bonilla A. La neutralidad axiológica de la ciencia como problema. En Rovaletti ML, ed. Etica y psicoterapia. Buenos Aires: Biblos; 1995: 21-27.

3. Langlois A. Ethique el connaissance; la recherche a viseé cognitive. En Parizeau MH, ed. Les fondémentes de la bioéthique. Bruxelles: De Boeck Universität; 1992: 153-168.

4. Dorey R, Castoriadis C, Enriquez E. et al El inconsciente y la ciencia. Buenos Aires: Amorrortu Editores; 1993.

5. Monod J. Le hasard de la necessité. Paris: Seuil; 1970.

6. Comité Consultatif National de Bioethique. Michaud J, ed.Étique et connaissance. Réflexions sur l'étique de la recherche biomedicale. Paris: La documentation Francaise; 1990.

7. Elias N. La civilisation des moeurs. Paris: Calmann-Lévy; 1973.

8. Rice A. The Witching Hours. New York: Knopf; 1990.

9. Memmi D. Les gardiens du corps. Dix ans de magistère bioéthique. Paris: Editions de L'Ecole des Hautes Etudes en Sciences Sociales; 1996.

10. Merleau Ponty M. Phénomenologie de la perception. Paris: Gallimard; 1945. 